\title{
Movimentos de implantação dos Núcleos Municipais de Educação em Saúde Coletiva (NUMESC) na $28^{\text {a }}$ Região de Saúde
}

\author{
Bibiana Moreira Carvalho \\ Fernanda Tomé Paim dos Santos ${ }^{1}$ \\ Maristela Soares De Rezende ${ }^{2}$ \\ Ana Zoé Schilling ${ }^{2}$ \\ Suzane Beatriz Frantz Krug ${ }^{2}$ \\ Leni Dias Weigelt ${ }^{2}$
}

\section{RESUMO}

A implantação dos Núcleos Municipais de Educação em Saúde Coletiva (NUMESC) é orientada pela Resolução 590/13 da Comissão Intergestora Bipartite (CIB). É uma estratégia para suprir as demandas de educação permanente nos serviços de saúde e trabalhar as questões da Saúde Coletiva com os diversos profissionais dos municípios. O objetivo deste estudo é descrever os movimentos de implantação dos NUMESCs na $28^{\mathrm{a}}$ Região de Saúde do Rio Grande do Sul (RS) e o processo de organização deste Núcleo no município de Venâncio Aires-RS. Trata-se de um estudo qualitativo descritivo, cujos dados foram obtidos através da participação em reuniões da Comissão de Integração Ensino-Serviço (CIES) e NUMESC deste município. Dos 13 municípios pertencentes a $28^{\text {a }}$ Região de Saúde, oito estão com os NUMESC instituídos. O primeiro município a assinar o termo de adesão, foi Venâncio Aires, que está se estruturando com reuniões sistemáticas e ações. O NUMESC de Venâncio Aires está se organizando e realizando as ações, apesar das dificuldades enfrentadas, incluindo as questões financeiras e visões contrárias em relação ao processo de construção coletiva. Os avanços que estão acontecendo demonstram a importância desses espaços que vem sendo reconhecidos por parte dos trabalhadores do município engajados neste objetivo.

Palavras chave: Educação Permanente. Saúde Coletiva. NUMESC.

\section{ABSTRACT}

The Resolution 590/13 of Comissão Intergestora Bipartite (CIB), guides the implementation of the Municipal Education Centers in Public Health (NUMESC). It is a strategy to meet the demands of permanent education services and work with the issues of Public Health with the various professionals of the municipalities.

\footnotetext{
${ }^{1}$ Alunas do Curso de Odontologia da Universidade de Santa Cruz do Sul - UNISC. ${ }^{2}$ Professoras do Curso de Enfermagem na Universidade de Santa Cruz do Sul.<lenid@unisc.br>
} 
The aim of this study is to describe the deployment movements of the 28th NUMESCs Health - Rio Grande do Sul (RS) Region and the process of organizing this Center in the city of Venâncio Aires. This is a descriptive qualitative study, whose data were obtained through participation in meetings of the Integration Committee Teaching-Service (CIES) and NUMESC. Eight of the 13 municipalities in the 28th Health Region, are with NUMESC instituted. The first municipality to sign the adhesion agreement was Venâncio Aires, which is structured with regular meetings and actions. The Venâncio Aires NUMESC is organizing and conducting actions, in spite of the difficulties, including financial issues and opposing views regarding the process of collective construction. The advances that are happening demonstrate the importance of these spaces has been recognized by the municipal workers engaged in this goal.

Keywords: Permanent Education. Public Health. NUMESC.

\section{INTRODUÇÃO}

A carência de processos de educação para os trabalhadores do Sistema Único de Saúde (SUS) leva a discussões nas diversas arenas decisórias municipais e regionais de saúde. Várias resoluções surgem a partir desses movimentos, entre elas, a Resolução 590/13 da Comissão Intergestora Bipartite (CIB), que orienta a implantação dos Núcleos Municipais de Educação em Saúde Coletiva (NUMESC), constituídos por atores de diversos segmentos da comunidade, com interação entre os movimentos estudantis e sociais, conselhos de saúde e intersetoriais, instituições de ensino e trabalhadores, formando assim um grupo multidisciplinar (CIB -RS, 2013). Esta é uma estratégia para suprir as demandas de educação permanente nos serviços e trabalhar com as questões da Saúde Coletiva com os diversos profissionais dos municípios.

O Ministério da Saúde, através da Política Nacional de Educação Permanente, indica estratégias para mudanças nos processos de formação e capacitação dos trabalhadores. Para que essas mudanças aconteçam é necessário que as propostas deixem de ser construídas isoladamente pelos níveis superiores e passem a ser discutidas e decididas pelos próprios trabalhadores, levando em consideração as reais necessidades de cada município. Esse novo modelo propõe que os diversos atores que constituem o setor da saúde se articulem e problematizem suas ações, o trabalho em equipe a atenção individual e coletiva e a organização do sistema como uma rede única. Tais métodos de se fazer e pensar os processos de formação e trabalho possibilitam transformações das práticas de educação e de saúde, buscando o aprimoramento e a eficiência (BRASIL, 2005). 
Assim, o objetivo do presente estudo é descrever os movimentos de implantação dos NUMESC na $28^{a}$ Região de Saúde do Rio Grande do Sul (RS) e o processo de organização deste Núcleo no município de Venâncio Aires - RS.

\section{FUNDAMENTAÇÃO TEÓRICA}

Considerando os avanços tecnológicos e os novos métodos para a realização do trabalho, é fundamental que os trabalhadores em saúde estejam envolvidos de maneira dinâmica e participativa no que diz respeito à gestão do trabalho e educação permanente para conceber positivamente as novas ferramentas que a tecnologia proporciona, articulando no seu processo de trabalho e somando conhecimentos na intenção de aprimorar o serviço em saúde (BRASIL, 2004).

A ideia da educação permanente está voltada para a prática educativa que se orienta pelo cotidiano dos serviços, baseando-se em reflexões críticas a respeito dos problemas da qualidade da assistência, garantindo a participação coletiva-multi-profissional e interdisciplinar, promovendo a construção de novos conhecimentos e intercâmbio de vivências. Isso demonstra e representa a vontade de transformar a rede pública de saúde em um espaço de ensino-aprendizagem (RODRIGUES, VIEIRA, TORRES, 2010).

A Política Nacional de Educação Permanente tem como um dos seus objetivos qualificar as práticas de formação, atenção, gestão e controle social/participação popular, tornando os trabalhadores aptos a buscar o conhecimento prático e teórico de suas atividades nos serviços de saúde. A saúde quando pensada e trabalhada como um todo torna as práticas do dia-a-dia acolhedoras e capazes de promover um ambiente de trabalho agradável e saudável, com profissionais sintonizados e realizando suas atividades de maneira coletiva. As reuniões de equipe são momentos de trocas reflexivas, de críticas construtivas sobre a realidade e a organização do trabalho no serviço público de saúde. Dessa forma, o processo de Educação Permanente em Saúde facilita o cotidiano de trabalho do profissional, contribuindo para melhorar a sua qualificação e sistematizar o atendimento ao usuário.

Para que as transformações no sistema educacional dos trabalhadores aconteçam, são necessárias mudanças na maneira de descobrir as reais demandas advindas dos trabalhadores. Com esse intuito, a Escola de Saúde Pública em parceria com a Secretaria Estadual de Saúde criou estratégias para a instituição dos Núcleos Municipais de Educação em Saúde Coletiva (NUMESC). Estes Núcleos deverão suprir a carência dos serviços ao trabalhar com a questão da Saúde Coletiva, em especial a Educação Permanente, com os diversos profissionais que 
compõem as unidades de Saúde de cada município de maneira loco-regional em que o próprio município seja gestor da sua estratégia e ação pedagógica (CIB-RS, 2013).

\section{MATERIAIS E MÉTODOS}

Trata-se de uma pesquisa qualitativa descritiva, cujos dados foram obtidos através da participação em reuniões da Comissão de Integração Ensino-Serviço da $13^{\mathrm{a}}$ Coordenadoria Regional de Saúde-RS (CIES 13), com sede no município de Santa Cruz do Sul, na qual participam representantes dos 13 municípios desta coordenadoria, bem como em documentos desta comissão, como atas e resoluções da CIR $13^{\text {a }}$ CRS-RS. Além disso, foi entrevistado um representante do Núcleo Regional de Educação em Saúde Coletiva (NURESC/13 ${ }^{\text {a }}$ CRS-RS).

A Pesquisa qualitativa proporcionou a percepção da realidade que não pode ser apenas quantificada e permitiu o aprofundamento dos significados. A análise dos conteúdos se deu a partir da pré-análise do material que objetivou a sua organização e através da leitura foram identificados informações que se destacaram pela repetição de seus enunciados, permitindo organizá-las em três categorias temáticas (MINAYO, 2006). As categorias, o movimento da EPS no âmbito da $28^{a}$ Região de Saúde-RS, a implantação dos NUMESC, e a organização do NUMESC no município de Venâncio Aires, são discutidas ao longo deste artigo.

\section{RESULTADOS E DISCUSSÃO}

\subsection{O movimento da EPS no âmbito da $28^{a}$ Região de Saúde-RS}

Os princípios que orientam e estabelecem as diretrizes do Sistema Único de Saúde, integralidade, universalidade, equidade, descentralização e participação popular sugerem transformações no sistema educacional dos profissionais da saúde para que consigam atender às necessidades das populações de maneira efetiva, proporcionando qualidade no cuidado em saúde.

Desta forma, surgem problematizações quanto à questão da Educação Permanente em Saúde, que anteriormente eram voltadas para programas de saúde com capacitações técnicas que, embora descentralizadas e desarticuladas, provocaram questionamentos e reflexões sobre a necessidade de mudanças nas práticas educativas e ações em serviço. No Estado do Rio Grande do Sul, em 1999, teve inicio o movimento de busca para a descentralização das ações de educação em saúde, com o objetivo de envolver e comprometer 
os municípios. Para a região dos Vales, a proposta de Educação Permanente surgiu com a Escola de Saúde Pública (ESP) que vislumbrava processos educativos, de acordo com a realidade, baseados em conceitos de autores que trabalham as práticas e o aperfeiçoamento por meio de trocas, pensando a organização e a gestão dos processos de trabalho como processos educativos.

A $13^{\text {a }}$ Coordenadoria Regional de Saúde $\left(13^{\mathrm{a} C R S}\right)$ juntamente com a Escola de Saúde Pública (ESP) desenvolveu estratégias no sentido de descentralizar as ações. O Núcleo Regional de Educação em Saúde Coletiva (NURESC) foi criado para promover ações, envolvendo os municípios e visando pensar as questões de saúde coletiva sob o olhar da educação. Essa proposta instiga o exercício da cidadania, favorecendo o entendimento sobre direitos, deveres e a participação social. Por motivos políticos, esse movimento não foi priorizado pela nova administração do governo do Estado do Rio Grande do Sul, desmotivando alguns trabalhadores.

Em 2004, foi instituída, pela Portaria GM/MS nº 198, a Política Nacional de Educação Permanente em Saúde como estratégia do SUS, para a formação e desenvolvimento de trabalhadores. Para a $28^{a}$ Região de Saúde-RS, esta Política foi apresentada pela ESP em

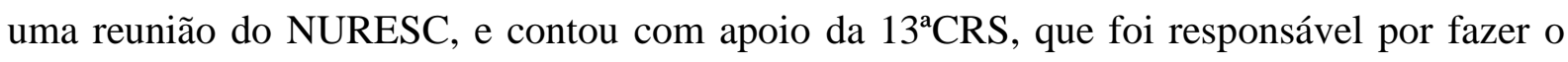
contato com os municípios, os incentivando e os estimulando a pensar quanto as suas realidades de educação.

No sentido de descentralizar as ações de educação em saúde, unir os municípios em regiões e promover a participação dos diversos segmentos da sociedade, foram propostos os Polos de Educação Permanente. Esses Polos tornavam possível o acesso de diversos parceiros da sociedade para a implantação de um SUS com alta responsabilidade com a qualidade da saúde, com a promoção da vida e com a valorização dos trabalhadores e dos usuários. Essas ações colocaram em evidência a necessidade de melhorias na formação para oo desenvolvimento dos trabalhadores que atuam no SUS, através da educação permanente, sugerindo a associação entre desenvolvimento individual e institucional; entre serviços e gestão setorial; e entre atenção e controle social, apontando a implementação dos princípios e das diretrizes constitucionais do SUS (CECCIM, 2004).

Os Polos de Educação Permanente constituíam um espaço para encontros e integração entre as regiões de saúde, permitindo que os processos de educação permanente fossem fortalecidos com o poder dos atores locais no esforço coletivo em prol de avanços na melhoria das condições de vida na região e nos municípios (KLEBA, COMERLATTO, COLLISELLI, 2007). Além disso, essas estratégias possibilitaram a visualização de uma nova 
perspectiva em relação às demandas das regiões, sendo as ações determinadas por quem tem o real conhecimento sobre cada município, e estipuladas pelos que fazem parte do contexto social, ou seja, cada trabalhador, cada cidadão, cada instituição de ensino que estejam engajados nas questões de saúde. Assim, ficou evidente que os municípios precisavam de um meio para definir as demandas de acordo com a realidade de cada um.

Portanto, os Polos iniciaram o processo de empoderamento dos atores sociais, pois permitiam um espaço de trocas e de sensibilização para a intervenção, bem como identificando os desafios e os potencias existentes em sua realidade concreta (KLEBA, COMERLATTO, COLLISELI, 2007). Atualmente, a CIES 13 tem investido esforços no sentido de sensibilizar seus membros para o desencadeamento de processos com ações voltadas à educação permanente em saúde. Em respeito às peculiaridades de cada município com reações e condutas distintas, o processo torna-se moroso.

\subsection{Implantação dos NUMESC}

A Resolução 590/13 da CIB-RS tem como objetivo a descentralização das ações de educação permanente em saúde, considerando os municípios mais próximos dos trabalhadores e inteirados do contexto da saúde local. Na $28^{a}$ Região de Saúde-RS, essa resolução foi apresentada para representantes dos 13 municípios que compõem esta divisão, em reuniões da Comissão de Integração Ensino-Serviço (CIES/RS), que acontecem na sede da $13^{\mathrm{a}}$ Coordenadoria Regional de Saúde, no município de Santa Cruz do Sul, RS. Os participantes da CIES são profissionais da saúde, dos setores administrativos, pesquisadores de grupos de estudos, representantes dos movimentos sociais e representantes do Estado.

As reuniões da CIES contam com a participação de diversos atores sociais, possibilitando pautas discutidas de maneira dinâmica e multidisciplinar. Ocorrem mensalmente com a finalidade de amparar os trabalhadores e emitir informações ao Estado e aos municípios. Em uma das reuniões desta comissão, foi apresentada e discutida a Resolução 590/13 da CIB e os recursos financeiros destinado aos municípios que implantarem ao NUMESC, de acordo com o número de habitantes, porém este recurso ainda não está disponível. Coube aos participantes levarem a ideia de implementação do NUMESC ao gestor, o do seu município.

Como este processo é novo no sistema público, a implantação do NUMESC está ocorrendo de forma lenta, construída nas reuniões referidas e nos municípios, com o engajamento dos trabalhadores da saúde. 
A Política Nacional de Educação Permanente em Saúde (PNEPS) apresenta algumas diretrizes que tratam das responsabilidades municipais na educação em saúde e norteiam alguns objetivos do trabalho a ser realizado pelos NUMESC. A PNEPS responsabiliza os municípios por formular e promover a gestão da educação permanente em saúde, seguindo os princípios da integralidade da atenção à saúde, criando meios de coordenar e executar essa política. Os municípios devem promover, em parceria com outros municípios, com o Estado e com a União, processos conjuntos de educação permanente em saúde, como maneira de articular e executar os projetos em rede, apoiar e incentivar a aproximação dos movimentos populares em saúde na formação dos profissionais de acordo com as necessidades sociais (BRASIL, 2009).

Essa política vem com o desafio de gerenciar experiências de aprendizagem que interessem aos sujeitos envolvidos, que permitam ligações no processo de compreensão e construção dos conhecimentos. Com isso, deseja criar modos de pensar inteligentes e criativos para beneficiar o desenvolvimento pessoal e social, e assim, estimular a capacidade de refletir e problematizar sobre as questões de saúde dos trabalhadores em serviço. A autonomia no processo de aprendizagem desenvolve essas capacidades e estimula o profissional a querer aprender e assim identificar a importância e a necessidade da formação permanente (RICALDONI, 2006).

Os NUMESC, por sua vez, podem auxiliar no desenvolvimento da educação permanente, estimulando os trabalhadores a pensarem sobre o contexto no qual estão inseridos, tornando-os pessoas mais cientes e críticas. Ao refletirem sobre o seu cotidiano, os problemas poderão ser identificados, juntamente com sua origem e assim, dentro deste núcleo, terão o espaço ideal para discutir e encontrar soluções coletivamente.

Atualmente, na $28^{\text {a }}$ Região de Saúde-RS, existem oito municípios que tem NUMESC instituído, ou seja, municípios que assinaram o termo de adesão. São eles: Venâncio Aires, Santa Cruz do Sul, Sinimbu, Gramado Xavier, Mao Leitão, Candelária, Rio Pardo e Passo do Sobrado.

A partir da motivação e engajamento de alguns trabalhadores, esta ideia foi levada até o gestor de cada localidade, que assinou o termo de adesão. Porém, nem todos que assinaram o termo, possuem NUMESC ativo e sim instituído. Os trabalhadores enfrentam dificuldades que os impedem de conseguir efetivar esse núcleo. Essas dificuldades foram relatas pelos trabalhadores durante as reuniões da CIES e apontam inclusive dificuldades para realização de reuniões. A carência de profissionais interessados em educação em saúde, a 
burocracia, a insatisfação com o trabalho e até mesmo a falta de conhecimento impossibilita que o NUMESC seja criado e fortalecido.

O estímulo aos trabalhadores da saúde é fundamental para o enfrentamento deste desafio de criar um espaço coletivo de discussão e reflexão voltado ao bem-estar de todos, importante para a construção do conhecimento e das mudanças que acontecerão no ambiente de trabalho e nas relações interpessoais partir destes diálogos.

Entretanto, apesar das dificuldades, alguns trabalhadores demonstram interesse em colocar em prática esta ideia e por isso, estão presentes nas reuniões da CIES, buscando informações burocráticas como decretos e portarias. Esse movimento expressa uma ação de educação permanente. Os profissionais estão se organizando entre eles e contando com o auxílio dos atores sociais para alcançar este objetivo; isso inclui os pesquisadores que através da pesquisa sobre educação permanente trouxeram à tona esse importante tema a ser discutido entre os gestores de saúde.

\subsection{A organização do NUMESC no município de Venâncio Aires - um exemplo}

Venâncio Aires foi um dos primeiros municípios a assinar o termo de adesão, em março de 2014. Este, por sua vez, vem se organizando e conta com diversos profissionais que integram este núcleo, como profissionais das Estratégias Saúde da Família, membros das secretarias de habitação, administração e assistência social do município e da residência multiprofissional (médico, psicólogo e nutricionista). A organização se dá por meio de um calendário de reuniões sistematizadas, apresentando uma pauta prévia aos participantes e permitindo aos mesmos contribuírem com os temas, através de colocações sobre seu cotidiano de trabalho. Essas reuniões possibilitam aos trabalhadores momentos de trocas coletivas entre colegas que muitas vezes compartilham dos mesmos anseios e contribuem um com o outro gerando maior conforto em seu dia-a-dia.

Surgem das reuniões mensais do NUMESC, reflexões sobre as ações necessárias para melhorar a qualidade no serviço prestado bem como para facilitar o trabalho. Essas ações pensadas pelo grupo resultam em projetos e eventos para o desenvolvimento da educação permanente adequados às necessidades, como por exemplo, o projeto "O processo de gestão do trabalho e de educação permanente em saúde dos trabalhadores que atuam no SUS no âmbito da $13^{\text {a }}$ Coordenadoria Regional de Saúde-RS" e o evento Encontro Regional de Educação Permanente em Saúde", ambos desenvolvidos em parceria com o Grupo de Estudos e Pesquisa em Saúde da Universidade de Santa Cruz do Sul-RS (GEPS/UNISC). 
Contudo, a participação de pesquisadores nas reuniões permitiu evidenciar que este município, mesmo enfrentando algumas dificuldades, necessidades de melhorias e recursos para as ações, estas são superadas devido ao engajamento dos trabalhadores, na busca de projetos que tornem resolutivas suas demandas de educação. Muitos são os debates e opiniões que emergem durante as discussões, considerados importantes para a construção do conhecimento, pois a partir destes diálogos e trocas de opiniões surgem as soluções e as maneiras mais adequadas para realizar as estratégias de educação em saúde. Essas trocas contribuem para definir as diretrizes de desenvolvimento das ações em educação e, em especial, na Saúde Coletiva.

Os movimentos em Venâncio Aires, para realizar mudanças, demonstram que para concretizar este desafio, além de recursos financeiros e técnicos, a força de vontade e a iniciativa dos trabalhadores são fundamentais no processo de transformação das práticas de saúde, uma vez que os mesmos são os verdadeiros protagonistas destas ações.

\section{CONSIDERAÇÕES FINAIS}

Os movimentos de implantação dos NUMESC na $28^{a}$ Região de Saúde do Rio Grande do Sul (RS) estão ocorrendo de forma lenta com interferência de fatores característicos de cada município, tais como, a carência de profissionais, de interessados em educação em saúde, a burocracia, a insatisfação com o trabalho e a falta de conhecimento sobre a importância da Educação Permanente em Saúde.

Quanto ao processo de organização deste Núcleo no município de Venâncio Aires RS há um engajamento dos trabalhadores que se reúnem sistematicamente, para discussão e organização do NUMESC, demonstrando as condições de informação e valorização dos mesmos em relação a esses espaços de aprendizado e construção coletiva.

O município de Venâncio Aires é um exemplo a ser seguido pelos demais que desejam tornar o NUMESC uma realidade. As dificuldades são enfrentadas por todos, mas é preciso saber articular os meios possíveis e construir mesmo que em passos lentos uma nova forma de pensar e trabalhar em saúde, para que assim, os princípios básicos que norteiam o Sistema Único de Saúde sejam finalmente colocados em prática.

No processo de gestão do trabalho, a educação permanente em saúde é um instrumento que auxilia a construção de novos desenhos na organização do trabalho. Os NUMESCs idealizam pensar as questões relacionadas à gestão do trabalho e a educação em saúde, através de trocas de ideias, análises críticas sobre as políticas públicas em saúde, entre 
os trabalhadores. Esses núcleos tem o papel de suprir as carências dos processos de educação em saúde e possibilitar aos trabalhadores o empoderamento para a gestão do trabalho e, consequentemente, resolver os problemas relacionados às demandas e à organização.

Os Polos de Educação Permanente constituíram, inicialmente, a maneira de organizar regionalmente a captação de demandas da educação em saúde. Na atualidade, é prioritário que os próprios municípios levem em consideração suas peculiaridades e os NUMESCs acolham as demandas e as ações.

A ideia de formar profissionais para atuar no SUS focados em um ensino técnico e individualizado, não se mantém e a presença de importantes atores como a Universidade e a Escola de Saúde Pública, torna o espaço para o aprendizado dinâmico e capaz de proporcionar a formação coletiva. Para que a saúde se dê de forma integral, como rege o princípio, é essencial que os profissionais tenham a sua formação específica, mas com um olhar amplo, adquirido no conhecimento coletivo. Aprender a trabalhar em equipe é primordial na formação dos profissionais, pois são nesses momentos que o conhecimento coletivo é construído.

O SUS tem criado estratégias para o cuidado da saúde coletiva e individual e isso vem beneficiando a saúde pública como um todo, pois traz novos conhecimentos para os trabalhadores sobre a orientação da Educação Permanente em Saúde, estimulando a participação ativa dos trabalhadores e gestores nas decisões sobre políticas públicas. A implantação do NUMESC também é uma dessas estratégias, pois garante que os profissionais estarão envolvidos nas decisões e investir em políticas públicas que assegurem os direitos dos usuários e dos próprios trabalhadores.

Cada município apresenta particularidades que devem ser consideradas ao elaborar as políticas de saúde voltadas pra cada região. Os núcleos municipais poderão, a partir do conhecimento da sua região, criar campanhas educativas, elaborar projetos de prevenção, organizar eventos de saúde, ou seja, os trabalhadores terão livre arbítrio para discutir e decidir sobre o que é importante e o que deve ser priorizado para sua comunidade.

\section{REFERÊNCIAS}

BRASIL, Ministério da Saúde. A educação permanente entra na roda: Pólos de Educação Permanente em Saúde: Conceitos e Caminhos a Percorrer. Brasília - DF: Ministério da Saúde, 2005. 36p. Acesso em outubro de 2015: <http://bvsms.saude.gov.br/bvs/publicacoes/educacao_permanente_entra_na_roda.pdf > 
Ministério da Saúde. Secretaria de Gestão do Trabalho e da Educação na Saúde. Departamento de Gestão da Educação em Saúde. Política Nacional de Educação Permanente em Saúde. Brasília: Ministério da Saúde. 2009.

Ministério da Saúde. Secretaria de Gestão do Trabalho e da Educação na Saúde. Departamento de Gestão da Educação na Saúde. Política de Educação e Desenvolvimento para o SUS Caminhos para a Educação Permanente em Saúde. Brasília: Ministério da Saúde, 2004.

COMISSÃO INTERGESTORES BIPARTITE (CIB-RS). Resolução $n^{\circ}$ 590/13. Secretaria da Saúde do Estado do Rio Grande do Sul, 2013.

CECCIM, R. B. Educação Permanente em Saúde: descentralização e disseminação de capacidade pedagógica na Saúde. Revista Mineira de Saúde Pública / Escola de Saúde Pública de Minas Gerais. Belo Horizonte, 2004. Acesso em outubro de 2015: <http://www.esp.mg.gov.br/wp-content/uploads/2009/07/revista05.pdf>

KLEBA, M. E.; COMERLATTO, D.; COLLISELlI E. Promoção do empoderamento com conselhos gestores de um Pólo de Educação Permanente em Saúde. Texto e contexto Enfermagem, Florianópolis, n. 2, v. 16, 2007.

MINAYO, M.C.S. O desafio do conhecimento: pesquisa qualitativa em saúde. São Paulo: Hucitec, 2006.

RICALDONI, C. A.; SENA, R. R. Educação Permanente: uma ferramenta para pensar e agir no trabalho de enfermagem. Revista Latino Americana de Enfermagem, Ribeirão Preto, n. 6, v. 14. nov./dez. 2006.

RODRIGUES, A. C. S.; VIEIRA, G. L. C.; TORRES, H. C. A proposta da educação permanente em saúde na atualização da equipe de saúde em diabetes mellitus. Revista Escola de Enfermagem da USP, São Paulo, n. 2, v. 44. 2010.

\section{Como citar este documento:}

CARVALHO, Bibiana Moreira et al. Movimentos de implantação dos Núcleos Municipais de Educação em Saúde Coletiva (NUMESC) na $28^{a}$ Região de Saúde. Revista Jovens Pesquisadores, Santa Cruz do Sul, v. 6, n. 1, jun. 2016. ISSN 2237-048X. Disponível em: 〈https://online.unisc.br/seer/index.php/jovenspesquisadores/article/view/7347>. Acesso em: doi:http://dx.doi.org/10.17058/rjp.v6i1.7347. 